\title{
The Personal Support Worker Program Standard in Ontario: An Alternative to Self-Regulation?
}

\author{
Le Cahier des normes pour le programme \\ Préposé aux services de soutien personnels en Ontario : \\ une solution à l'autoréglementation?
}

\author{
एक \\ CHRISTINE KELLY, PHD \\ Banting Postdoctoral Fellow, Institute of Feminist and Gender Studies \\ University of Ottawa \\ Ottawa, ON \\ IVY LYNN BOURGEAULT, PHD \\ Professor, Telfer School of Management \\ CIHR Research Chair in Gender, Work and Health Human Resources \\ University of Ottawa \\ Ottawa, ON
}

\begin{abstract}
Personal support workers (PSWs) provide hands-on assistance in a variety of long-term care and community settings. The question of whether PSWs should become regulated similar to other self-regulating health professions is a perennial concern in policy circles, especially because of the intimate nature of their work and the potential for abuse of clients and workers. This article explores a chain of policy decisions around PSWs in Ontario culminating in the creation of a common educational standard for PSW programs, titled the PSW Program Standard. We argue that these policy developments may represent an alternative pathway to self-regulation of an essential workforce.
\end{abstract}

\section{Résumé}

Les préposés aux services de soutien personnels (PSSP) apportent une aide pratique dans une variété d'établissements de soins de longue durée et communautaires. La question à savoir si 
The Personal Support Worker Program Standard in Ontario: An Alternative to Self-Regulation?

les PSSP devraient faire l'objet d'une réglementation, à l'instar des autres professionnels de la santé autoréglementés, est récurrente dans les cercles politiques, en particulier en raison de la nature intime de leur travail et des possibilités d'abus pour les clients ou les travailleurs. Cet article examine une chaîne de décisions politiques relatives aux PSSP en Ontario, laquelle se termine par la création de normes éducatives pour les programmes destinés aux PSSP, soit le Cahier des normes pour le programme PSSP. Nous avançons que le développement des politiques peut constituer une démarche de remplacement à l'autoréglementation pour ce type de main-d'œuvre essentielle.

$\mathrm{P}$ ERSONAL SUPPORT WORKERS (PSWS) ARE A CADRE OF CARE WORKERS WHO ASSIST with the activities of daily living for older adults and people with disabilities in longterm care homes, retirement homes and community settings. Writing in the UK context, Saks and Allsop (2007: 165) define support workers as a diverse "group who work[s] across the health/social and the formal/informal care boundary." The demand for PSWs in Canada is expanding due to our aging demographics and economic pressures to lower healthcare costs by shifting tasks from higher- to lower-paid workers. Indeed, the number of PSWs is said to eclipse the number of nurses in the healthcare system. In Ontario, the Ministry of Health and Long-Term Care (MOHLTC) estimated that there are 90,000 people working as PSWs, with many job openings in this field. It is important to delineate, however, that many PSWs work on a contractually, part-time or on-call basis, creating difficult working conditions and making PSWs difficult to count. It is also noteworthy that these workers are largely women and over-represented by racialized people and/or immigrants to Canada (Lum et al. 2010; PSNO 2012).

The question of whether this growing body of workers should become self-regulating health professionals is a perennial concern in policy circles, especially because of the intimate nature of their work and the possibility for abuse of both clients and workers. Drawing together documentary materials from the public domain, this article explores the Ontario government's decision to develop the PSW Program Standard, a common educational standard that was released in July 2014 and is the most recent development in a chain of policy decisions. We argue that the policy developments around PSWs in Ontario move towards standardization and the creation of infrastructure that may represent an alternative pathway to self-regulation.

\section{A Brief Background on Forms of Regulation}

Adams (2010) identifies three types of professional regulation in Canada: self-regulation with autonomous regulatory boards of practitioners utilized by groups such as doctors and lawyers; title regulation in which a regulatory body of practitioners requires workers to register and 
provide proof of training to claim a restricted title, but with limited authority in the field; and occupational regulation where governments create a board to monitor field membership, most commonly used for skilled trades. Adams' (2010) work highlights that there are many ways to regulate professions and that there is an inherent hierarchy from self- to title to occupational regulation. In the case of health professions, occupational regulation is rarely used in contrast to self- and title regulation.

Considering the situation of PSWs in this regulatory context is not a simple exercise. As in other locations, most studies of regulation focus on "fully fledged registered professions" and do not consider the ambiguous position of PSWs (Saks and Allsop 2007). Some might argue that PSWs are more akin to skilled trade workers than medical professionals, but PSWs are often regarded as members of the healthcare hierarchy, falling just "below" registered practical nurses (RPNs). Educational programs reinforce this position through bridging programs where PSWs with recognized certificates are given credit towards an RPN diploma. In the case of Ontario, many of the activities of PSWs fall under the controlled acts under the Regulated Health Professions Act, although to perform them, they must be delegated. In sum, PSWs are an anomaly that is difficult to categorize in attempts to distinguish health professions from other regulated occupations.

\section{The Chain of Policy Developments Leading up to the PSW Program Standard}

The context leading up the educational standard indicates increasing social and political pressure to address the intricate problems of long-term care, even if solutions are not readily available or agreed upon. In 2006, the Health Professions Regulatory Advisory Council (HPRAC) considered the question of PSW self-regulation. The report concluded that PSWs should not become a self-regulated health profession owing to factors including ambiguity around their scope of practice, non-standardized knowledge held by the occupation, lack of consensus among key stakeholders, and the possibility that pursuing regulation would entail retraining and human resourcing costs (HPRAC 2006). Foregrounding discussions of PSW regulation is the increasing levels of acuity of clients in long-term care facilities, which is in turn linked to political and medical commitments to shorter hospital stays (HPRAC 2006). Personal support work has become much more complicated, and according to the HPRAC report, transitioning PSWs to a regulated health profession would not be the appropriate response to their changing job requirements.

\section{Developing a PSW Registry}

Although the issue of regulation was put on hold, the MOHLTC followed the example of British Columbia and created a PSW Registry in May 2011 commissioning the Ontario Community Support Association (OCSA) to establish the platform (MOHLTC 2011). The Registry broadly aims: "to identify and acknowledge PSWs and individuals providing personal support services for their role in healthcare and for their daily contributions to some 
The Personal Support Worker Program Standard in Ontario: An Alternative to Self-Regulation?

of Ontario's most vulnerable populations" (PSW Registry 2015). In practice, the Registry collects basic information on the registrants related to employment history and educational background, includes a job board, and a referral process for complaints. The personal information is only available to employers and for limited research purposes (PSW Registry 2015). It is mandatory for PSWs who work in publicly funded home care settings to register and over 30,000 have done so (Lum 2013). This requirement will extend to other work settings in the coming years (OCSA 2012).

Generally speaking, the establishment of the Registry has been well-received by community groups representing PSWs. The Canadian Union of Public Employees (CUPE) Ontario, however, objects to the Registry's emphasis on employer needs and suggests it does little to benefit PSWs. Coordinators of the Registry are working to clarify the overall goals, monitor mandatory registration, confront potential issues of confidentiality and to specify whether the Registry will be used to handle complaints and dismissals (Laporte and Rudoler 2013; OCSA 2012). The latter issues move more directly into the realm of self-regulation, and the approach to these issues will illuminate the regulatory intent of the PSW Registry.

\section{Establishing a PSW education standard}

Working as a PSW in Ontario does not necessarily require formal training, nor passing a standardized examination. There are an array of training programs offered in public, private and vocational colleges, school boards and online, as well as an established practice of on-thejob training, creating a complex educational landscape. Scholars and community groups note that there is remarkable variability in the content among PSW training programs, resulting in differential skills, responsibilities and knowledge (HPRAC 2006; Keefe and Légaré 2011; Laupacis and Born 2012; Lilly 2008). In 2012, the Association of Canadian Community Colleges (ACCC)argued for a national educational standard to address worker mobility and international training (ACCC 2012; NACC PSW 2013).

In light of the increasing concerns voiced by a number of stakeholder organizations with the variability of PSW preparation, the Ontario Ministry of Education issued a Memorandum on April 5, 2013, announcing the development of an educational standard for PSW programs, following similar moves in Nova Scotia and British Columbia (ACCC 2012). Consultations and an online survey about the Ontario standard were carried out by the MOHLTC in May-June 2013, the results of which were not released to the public. The consultations did, however, yield three publicly available responses from the Personal Support Network of Ontario (PSNO), CUPE Ontario and the Ontario's Nurses' Association (ONA), all of which were strongly in favour of establishing the standard (CUPE 2012a; ONA 2012; PSNO 2012). CUPE (2012a), for example, saw the development of a standard as a way to rein in for-profit educational providers. PSNO and ONA did, however, express concern for how the standard will affect those already working as PSWs. PSW work is poorly paid and often sporadic, raising concerns about the ability of working PSWs to return to school if required by the establishment of a standard. 
The task of developing the standard was passed to the Ministry of Training, Colleges and Universities (MTCU), who based the new standard on the existing standards and a consultation process that involved focus groups and the formation of a Technical Working group. Once the Program Standard was released in July 2014, the programs were given a year to update their curriculum and submit to the appropriate department or ministry for approval (as different programs fall under different jurisdictions, e.g., the school boards report to the Ministry of Education, public colleges report to MTCU).

\section{Implications for PSW Regulation}

The recent policy developments related to PSWs culminating with the Program Standard may represent alternative measures to standardize, monitor and improve this field without PSWs becoming a self-regulated health profession.

The pursuit of self-regulation typically involves an organized group of workers to advocate, develop official policies and consult on legislative changes (Bourgeault 2006 on midwifery). While there are some organizations that represent PSWs in Ontario, for example, PSNO, CUPE and the Ontario Community Support Association (OCSA), these organizations are not actively working towards self-regulation. As suggested by informal discussions on social media discussion boards associated with the aforementioned organizations, PSWs themselves express interest in becoming regulated, but expect it to "come from above" (e.g., PSNO Facebook group: https://www.facebook.com/groups/53248778815/).

Ontario is not yet in a stage of title regulation as defined by Adams (2010) for PSWs. It is not mandatory for PSWs to apply to the registry, nor to have a PSW certificate if they do register, nor for employers to hire registered PSWs, and most significantly, there is no practitioner board overseeing the registry. Owing to the shortfalls of the current long-term and community care landscape, there remains an incentive for working as or hiring private care workers, a tendency that will be reinforced by the Ontario directive towards self-managed home care (Grant 2015). In the UK, Saks and Allsop (2007) do not recommend licensure of support workers, but emphasize enhancements in training and advocate for the introduction of a registry similar to what Ontario has done.

As noted above, state-led occupational regulation has taken place for skilled trades such as hairdressers and insurance brokers, but not for groups in the health and social care sector. Thus, the provincial government would be forging new ground in taking this approach. A key implication of state regulation noted in the literature is the issue of job loss (Kleiner 2011), and employers already report a lack of PSWs and a high turnover rate (Denton et al. 2006; PSNO 2012).

From a health economics perspective, regulation leads towards more expensive human resourcing. In an American study on the effects of occupational licensing, Kleiner and Krueger (2010) found that licensing increases wages by approximately $15 \%$, and further, in combination with unionization, licensing increases wages by $24 \%$. There are some indications of the relevance to the PSW case with the announcement of the MOHLTC to raise the minimum 
wage for PSWs working in publicly funded settings from $\$ 14 /$ hour to $\$ 16.50 /$ hour. Kleiner and Kruger (2010) also found that without unionization, licensing alone does not reduce wage dispersion across a field, a major issue in current PSW work. While fraught with problems in implementation, the PSW wage increase represents an alternative mechanism to address low and disparate wages at a lower cost than what could be associated with licensure.

The evidence on whether regulation improves patient services is inconclusive, according to Kleiner (2011), although his study considers many occupations beyond PSW work. In sum, there are a number of disincentives for state-initiated regulation of the sector, namely, the risk of slowing job growth, increase in costs and inconclusive evidence about addressing wage dispersion or improving patient services.

\section{Conclusion}

The Ontario PSW Program Standard has the potential to simplify an educational landscape, while adding another mechanism to prevent this field from becoming a self-regulated health profession. Depending on the setting, PSW work is highly regulated in other ways, for example, through legislation, ministry guidelines and evaluations. The long-term care landscape is complicated by factors such as individual life stage and circumstance, geographical setting, precarious working conditions for PSWs and settings of support ranging from highly autonomous direct funding attendant service options to more closely monitored long-term residential settings. Policy decisions around this sector must thus build-in flexibility to reflect the changing needs of long-term care in Ontario.

Correspondence may be directed to: Christine Kelly, PhD, Banting Postdoctoral Fellow, Institute of Feminist and Gender Studies, University of Ottawa, Ottawa, ON; tel.: (613) 562-5800, ext. 7339; e-mail: Christine.Kelly@uottawa.ca.

\section{References}

Adams, T.L. 2010. “Profession: A Useful Concept for Sociological Analysis?” Canadian Review of Sociology 47(1): 49-70.

Association of Canadian Community Colleges (ACCC). 2012."Canadian Educational Standards for Personal Care Providers." Retrieved April 19, 2015. < http://www.collegesinstitutes.ca/what-we-do/canadian-partnerships/ national-educational-standards-for-personal-care-providers $/>$.

Bourgeault, I.L. 2006. Push! The Struggle to Integrate Midwifery in Ontario. McGill-Queen's University Press, Montreal, QC.

Canadian Union of Public Employees (CUPE). 2012a. “Submission Regarding Personal Support Worker (PSW) Educational Standards in Ontario." Retrieved February 19, 2014. <http://www.cupe.on.ca/a4917/Submission\%20 on\%20Personal\%20Support\%20Worker\%20educational\%20standards\%20in\%20Ontario.pdf >.

Canadian Union of Public Employees (CUPE). 2012b. "Personal Support Worker (PSW) Registry Notice to Health Care Members of CUPE Ontario and OCHU." Retrieved February 19, 2014. <http://www.cupe.on.ca/ a4938/CUPE\%20OCHU\%20letter.pdf>

Denton, M., I.U. Zeytinoglu, S. Davies and D. Hunter. 2006. “The Impact of Implementing Managed Competition on Home Care Workers' Turnover Decisions." Journal of Healthcare Policy 1(4): 106-23. doi: 10.12927/ hcpol.2006.18256. 
Grant, K. 2015 (May 13). “Ontario Vows 'Self-Directed' Home Care; Pilot Project Would Give Patients or Their Caregivers Money to Spend on Services of Their Choosing." The Globe and Mail. Retrieved October 10, 2015. <http://www.theglobeandmail.com/news/national/ontario-health-minister-expected-to-address-scathing-reporton-home-care/article24415170/>.

Health Professions Regulatory Advisory Council (HPRAC). 2006."The Regulation of Personal Support Workers (Final Report to the Minister of Health and Long-Term Care)." Retrieved February 19, 2014. < www.hprac.org/ en/reports/resources/PSW-FinalReportSept27-06.pdf>.

Keefe, M. M. and J. Légaré. 2011. “Home Support Workers: Human Resource Strategies to Meet Chronic Care Needs of Canadians: Final Report." Retrieved December 12, 2014. <www.msvu.ca/site/media/msvu/HSW\%20 HR\%20Strategies\%20Project_Final\%20Report_June\%202011.pdf >.

Kleiner, M.M. 2011. Occupational Licensing: Protecting the Public Interest or Protectionism? Kalamazoo, MI: W.E. Upjohn Institute for Employment Research.

Kleiner, M.M. and A.B. Krueger. 2010. "The Prevalence and Effects of Occupational Licensing." British Journal of Industrial Relations 48(4): 676-87.

Laporte, A. and D. Rudoler, 2013. Assessing Ontario's Personal Support Worker Registry. Health Reform ObserverObservatoire des Réformes de Santé 1(1). doi:http://dx.doi.org/10.13162/hro-ors.01.01.02.

Laupacis, A. and K. Born. 2012. “Ontario's Plan for Personal Support Workers." Retrieved February 19, 2014. <healthydebate.ca/2012/05/topic/community-long-term-care/personal-support-workers >.

Lilly, M.B. 2008. "Medical versus Social Work-Places: Constructing and Compensating the Personal Support Worker across Health Care Settings in Ontario, Canada." Journal of Gender, Place and Culture 15(3): 285-99. doi: 10.1080/09663690801996288.

Lum, J. 2013. “Ontario PSW Registry Data Analysis Results.” Retrieved April 4, 2014. <http://www.ryerson.ca/ crncc/knowledge/events/pdf/PSW\%20Registry\%20Data\%20Analysis\%20Results\%20Final.pdf>.

Lum, J., J. Sladek and A. Ying. 2010. “Ontario Personal Support Workers in Home and Community Care: CRNCC/PSNO Survey Results." Retrieved February 19, 2014. <www.crncc.ca/knowledge/factsheets/pdf/ InFocus-Ontario\%20PSWs\%20in\%20Home\%20and\%20Community\%20Care.pdf >.

Ministry of Health and Long-Term Care (MOHLTC). 2011. “Ontario Creating Registry for Personal Support Workers." Retrieved February 19, 2014. <http://news.ontario.ca/mohltc/en/2011/05/ontario-creating-registryfor-personal-support-workers.html>.

National Association of Certified Caregivers/Personal Support Workers (NACC PSW). 2013.“CPSW Information." Retrieved February 19, 2014. <www.naccpsw.org>.

Ontario Community Support Association (OCSA). 2012.“The Ontario Personal Support Worker Registry: Public Report." Retrieved February 19, 2014. <www.crncc.ca/knowledge/related_reports/pdf/ontario-psw-registry-public-report-sep-2012.pdf>.

Ontario Nurses' Association (ONA). 2012."Submission to the PSW Educational Standards Consultation." Retrieved February 19, 2014. <http://www.ona.org/documents/File/politicalaction/ONA_Submission_ PSWEducation_20120518.pdf>

Personal Support Network of Ontario (PSNO). 2012."PSNO Submission for the Consultations on Educational Standards for Personal Support Workers." Retrieved February 19, 2014. <www.psno.ca/ uploads/1/0/1/9/10197937/psno_submission_for_the_psw_educational_standards_review_may_2012_ final.pdf $>$.

PSW Registry. 2015. Retrieved April 18, 2015. <http://pswregistry.org>.

Saks, M. and J. Allsop. 2007. “Social Policy, Professional Regulation and Health Support Work in the United Kingdom." Social Policy and Society 6(2): 165-77. 